\title{
Pain And The Use Of Gabapentinoids In German Nursing Home Residents - Results From An Analysis Based On Statutory Health Insurance Data
}

This article was published in the following Dove Press journal: Journal of Pain Research

\author{
C Bantel ${ }^{1,2}$ \\ F Hoffmann (iD) ${ }^{3}$ \\ K Jobski ${ }^{3}$ \\ 'Department of Anesthesiology, Critical \\ Care, Emergency and Pain Medicine, \\ Universität Oldenburg, Klinikum \\ Oldenburg, Oldenburg, Germany; \\ ${ }^{2}$ Department of Surgery \& Cancer, \\ Anaesthetics Section, Imperial College \\ London, London, UK; ${ }^{3}$ Department of \\ Health Services Research, Carl Von \\ Ossietzky University Oldenburg, \\ Oldenburg, Germany
}

Background: Gabapentinoids (gabapentin and pregabalin) are psychoactive medications that are increasingly used for different conditions. Since there is evidence that psychotropic drugs, in general, are often inappropriately prescribed in elderly patients, we aimed to determine frequency and indications of gabapentinoid prescribing for nursing home residents.

Methods: We analyzed data from a large German statutory health insurance database. Included were records from people $\geq 65$ years-of-age, who were admitted to a nursing home between January 2010 and December 2014. We determined the number and proportion of common indications for on- and off-label prescriptions, the most frequent co-medications, and the characteristics of patients and prescribers.

Results: Of 127,277 residents, 9539 (7.5\%) received gabapentinoids and 4852 initiated treatment $(4.0 \%$; with $66.3 \%$ pregabalin). Median age of gabapentinoid initiators was 84 years $(78.5 \%$ females). In these users, on-label prescribing was found in $57.4 \%$, predominantly for neuropathic pain. Other painful conditions were also chief causes $(84.7 \%)$ for offlabel prescribing. Gabapentinoids were mainly started by general practitioners $(64.5 \%)$ while pain specialists contributed $<2 \%$. Forty-six percent of users received additional opioids and in $27.5 \%$ gabapentinoids were prescribed only once.

Conclusion: Gabapentinoids were frequently used in nursing home residents. Regular coprescribing with opioids and psychotropic drugs might indicate employment to improve pain or assist treatment of conditions that are frequently associated with disruptive behavior such as dementia. However, more research is needed to better understand decision-making regarding gabapentinoid prescribing, especially in view of aggressive marketing, uncertain analgesic effects, problematic side effects, and uncritical use in the elderly.

Keywords: gabapentinoids, prescribing, elderly, nursing home, pain management

\section{Introduction}

Blockade of presynaptic voltage-gated calcium channels containing $\alpha 2 \delta 1$-subunits to reduce excitatory neurotransmitter release has become an increasingly popular pharmacological principle that is employed for a variety of diseases and conditions. ${ }^{1}$ The gabapentinoids, gabapentin and pregabalin, as the currently clinically available compounds in this class of medications are hence being used or have been trialed for management of for instance anxiety and bipolar disorders, behavioral and psychological symptoms of dementia (BPSD), chronic pruritus, epilepsy, hiccups, hot flashes, refractory cough, restless legs syndrome, spinal muscular atrophy, substance abuse disorders, and tinnitus. ${ }^{2-4}$ They are particularly popular in pain medicine and are
Correspondence: C Bantel Universitätsklinik für Anästhesiologie, Intensiv-, Notfallmedizin und Schmerztherapie, Universität Oldenburg, Klinikum Oldenburg Campus, RahelStraus-Strasse 10, Oldenburg 26133, Germany

Tel +49 44I 403 77I73

Fax +494414032774

Email carsten.bantel@uni-oldenburg.de
Journal of Pain Research 2019:12 3|75-3184

3175

DovePress $f y$ in $\boldsymbol{v}$

http://doi.org/10.2147/IPR.S221579 
therefore employed for the treatment of fibromyalgia, headaches, osteoarthritis, and post-operative as well as peripheral and central neuropathic pain. ${ }^{2,5,6}$ However, a considerable proportion of these uses are off-label. Off-label uses are uses outside of the approved licenses of the respective drug. They might be problematic because effectiveness and safety are not well supported by evidence. So far gabapentin, for instance, is only approved for the management of partial seizures and neuropathic pain associated either with diabetes (peripheral neuropathy) or herpes zoster infections (postherpetic neuralgia). ${ }^{7}$ Pregabalin, which was introduced to the market 10 years after gabapentin, is currently licensed for the treatment of peripheral and central neuropathic pain, partial seizures, and generalized anxiety disorders in Europe. ${ }^{7}$

Although generally regarded as being well tolerated, both drugs can nevertheless induce side effects that might considerably interfere with quality of life and patient safety. ${ }^{2,8,9}$ As psychoactive compounds, their use might be associated with cognitive impairment, drowsiness, and dizziness, particularly in the elderly population. ${ }^{9}$ Consequently, they might increase the risk of falls or further aggravate the detrimental neurological effects (drowsiness, sedation, somnolence) of other centrally acting medications such as opioids, antidepressants, or sedatives. ${ }^{10,11}$ These adverse events appear even more important in light of recent publications challenging the clinical value of these compounds. ${ }^{12}$

Because popularity of gabapentinoids is rising and because of evidence that psychotropic drugs are often inappropriately prescribed for elderly patients, monitoring of their correct use and identification of potential problematic developments become increasingly important. ${ }^{13}$ This applies especially to nursing home residents as they are regarded as highly vulnerable due to their common multiple health problems, frequent polypharmacy, and their often lacking ability to express their needs. ${ }^{13,14}$

The aims of the present study therefore were (a) to determine the frequency of prescribing of gabapentinoids for residents newly admitted to nursing homes and the characteristics of those patients, (b) to describe what indications and clinical contexts lead to the use of gabapentinoids, and (c) to identify the specialty of the prescribers initiating treatment as well as prescribing patterns.

\section{Methods}

\section{Data Source}

After approval by the ethics committee of Carl von Ossietzky University Oldenburg, Germany (064/2016), we used data from the "DAK-Gesundheit", a large statutory health insurance (SHI) fund enrolling about six million persons (over seven percent of the German population). Data include demographic characteristics as well as information on in- and outpatient diagnoses, treatments and procedures, outpatient prescriptions, and care level. Diagnoses are based on the German modification of the International Classification of Diseases, 10th revision (ICD-10-GM). Outpatient diagnoses including the diagnostic certainty (confirmed/suspected/ruled out/status post) are reimbursed on a quarterly basis (i.e., 3 months) whereas inpatient data encompassing main, ancillary, and secondary diagnoses can be referred to the dates (i.e., admission and discharge) of the respective hospital stay. Prescription data are limited to drugs reimbursed by the SHI. Only drugs prescribed by a physician and dispensed by a pharmacy are included in the data. Prescriptions can be linked to the Anatomical Therapeutic Chemical (ATC) Classification System and the defined daily dose (DDD) through the central pharmaceutical number.

This study was based on persons aged 65 years or older who were admitted to a nursing home between January 1, 2010, and December 31, 2014, and had been continuously insured in the year preceding nursing home admission.

Since this study was based on anonymous data, patientinformed consent was not required by German regulations.

\section{Gabapentinoid-Treated Patients And New User Cohort}

We searched the database for all residents who received at least one prescription of either gabapentin (ATC code N03AX12) or pregabalin (N03AX16) during nursing home stay. Patients who had not received any gabapentinoid the year before their first prescription after nursing home admission (index prescription) were considered new users.

Patients entered the new user cohort on the day of the index prescription and were followed until the first of the following dates: (a) end of insurance, (b) death, or (c) end of study period (December 31, 2014).

\section{Covariates Including Potential Indications}

For the new gabapentinoid users, we determined demographic characteristics for each patient as well as the care level ranging from $0 / 1$ (limited daily living skills/substantial need of care) to 3 (most intense need of care) at the day of the index prescription. Based on inpatient and confirmed outpatient diagnoses, comorbidity and potential 
indications for gabapentinoid use were analyzed in the quarter of the index prescription and the preceding quarter. We considered epilepsy and neuropathic pain as on-label indications for both drugs and additionally anxiety disorders for pregabalin. ${ }^{15,16}$

We further included off-label indications for pain management such as back pain, arthritis, cancer, and "pain not elsewhere classified" into our analysis using categories suggested by Freytag et $\mathrm{al}^{17}$ as well as other diagnoses such as depression or restless legs syndrome (see Supplementary Table 1 for all codes used).

Prescriptions of co-medications encompassing, for instance, opioids and antidepressants were assessed for the time of the index prescription (i.e., 30 days before until 30 days following the index prescription). This also included the total number of drugs (based on the 7 th level of the ATC code) a patient was receiving.

\section{Statistical Analyses}

Prescription prevalence and incidence of gabapentinoid use were calculated per 100 persons stratified by age group and sex. The prescription prevalence was defined as the number of patients receiving any gabapentinoid drug divided by the number of nursing home residents contributing to the respective group. Accordingly, the incidence was calculated by using the number of new gabapentinoid users (not receiving any gabapentinoid the year before nursing home admission) instead as numerator and excluding all prevalent gabapentinoid users from the denominator. Wilson score confidence intervals (CI) were calculated as described by Newcombe et al. $^{18}$

In the new user cohort, we summarized baseline characteristics and utilization of treatment stratified by the index prescription (pregabalin vs gabapentin) using descriptive statistics (median, interquartile range (IQR), and percentages). We assessed whether treatment with gabapentinoids changed during nursing home stay, meaning if patients switched between the two agents or had their doses adjusted. Therefore, distinct prescribed strengths were added up per prescription date and compared with a patient's other prescription dates (i.e., pregabalin $25 \mathrm{mg}$ and $50 \mathrm{mg}$ prescribed on the same day were considered equal to pregabalin $75 \mathrm{mg}$ prescribed on another day). The duration of gabapentinoid treatment was assessed based on two different methods: First, we used the dispensed DDDs assuming that a patient's daily dose was one DDD. Second, we estimated the duration from the number of dispensed units (e.g., tablets or capsules) assuming that one unit was administered three times a day (irrespective of the drug's strength). Based on a patient's time of follow-up, we further calculated the proportion of days covered with gabapentinoids. Since inhospital medications with a few exceptions were not included in the database, the days a patient was hospitalized were excluded from analysis.

Analyses were performed using SAS, version 9.4 (SAS Institute Inc., Cary, NC).

\section{Results}

\section{Prevalence And Incidence Of Use}

From 127,277 residents newly admitted to a nursing home between 2010 and 2014, 9539 received at least one gabapentinoid during their stay (prescription prevalence: $7.5 \%$; 95\% CI: 7.4-7.6\%). The prevalence decreased from $12.0 \%$ (95\% CI: $11.1-13.0 \%$ ) in residents aged 65 to 69 years to $3.5 \%(95 \%$ CI: $3.0-4.0 \%)$ in the oldest group aged 95+ years. Women received respective treatment more often than men $(7.7 \%$ vs $6.8 \%$; Figure 1$)$. During the study period, the prevalence of gabapentinoid use increased steadily from $4.7 \%$ (95\% CI: $4.4-5.0 \%$ ) in 2010 to $6.6 \%$ (6.5-6.8\%) in 2014 (2012: 5.9\%; 5.7-6.1\%).

After excluding all prevalent gabapentinoid users $(n=4687)$, a total of 4852 patients (out of $n=122,540$ ) either initiated pregabalin $(66.3 \%)$ or gabapentin $(33.6 \%)$ resulting in an overall prescription incidence of $4.0 \%$ (95\% CI: 3.9-4.1\%, Table 1). The incidence dropped from $6.3 \%(95 \% \mathrm{CI}: 5.7-7.1 \%)$ in the group of residents aged 65 to 69 years to $2.2 \%(95 \% \mathrm{CI}: 1.8-2.6 \%)$ in the oldest age group (Figure 1). Women were more likely to initiate gabapentinoids than men $(4.2 \%$ vs $3.4 \%)$.

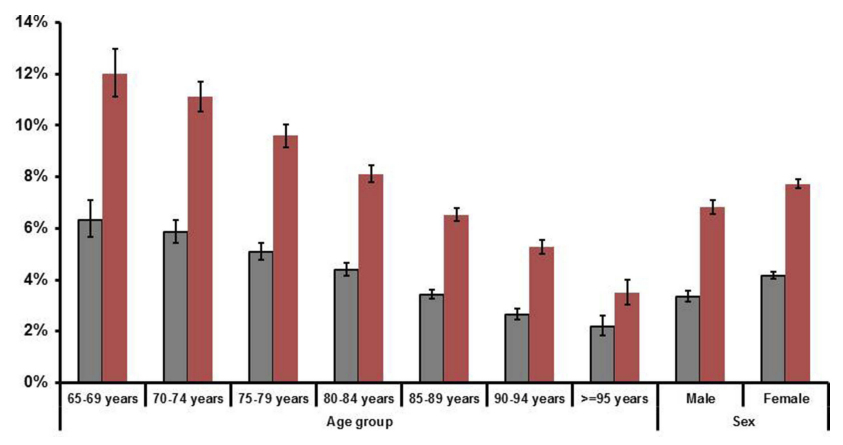

Figure I Incidence and prevalence of gabapentinoid prescriptions.

Notes: Gray bars: incidence; red bars: prevalence of gabapentinoid prescriptions. Data show incidence and prevalence, respectively, and 95\% confidence intervals per age and sex group. 
Table I Characteristics Of Incident Users At Index Prescription

\begin{tabular}{|c|c|c|c|}
\hline & Pregabalin Users $(\mathbf{N}=3219)$ & Gabapentin Users $(N=1629)$ & Total $(N=4852)^{a}$ \\
\hline Median age at index prescription (IQR) & $83(77-88)$ & $84(78-89)$ & $84(77-88)$ \\
\hline \multicolumn{4}{|l|}{ Sex; n (\%) } \\
\hline Male & 688 (21.4\%) & 356 (21.9\%) & 1045 (21.5\%) \\
\hline Female & $2531(78.6 \%)$ & $1273(78.2 \%)$ & 3807 (78.5\%) \\
\hline \multicolumn{4}{|l|}{ Care level at index prescription; n (\%) } \\
\hline $0-1$ & $1543(47.9 \%)$ & $852(52.3 \%)$ & $2398(49.4 \%)$ \\
\hline 2 & 1309 (40.7\%) & 624 (38.3\%) & 1934 (39.9\%) \\
\hline 3 & $367(11.4 \%)$ & $153(9.4 \%)$ & $520(10.7 \%)$ \\
\hline \multicolumn{4}{|l|}{ Medical conditions ${ }^{\mathbf{b}} ; \mathrm{n}(\%)$} \\
\hline Dementia & $1687(52.4 \%)$ & $806(49.5 \%)$ & $2496(5 \mathrm{I} .4 \%)$ \\
\hline Tendency to fall & $445(13.8 \%)$ & $222(13.6 \%)$ & $667(13.8 \%)$ \\
\hline Renal disease & $1309(40.7 \%)$ & $627(38.5 \%)$ & 1938 (39.9\%) \\
\hline Heart failure & $|28|(39.8 \%)$ & $626(38.4 \%)$ & 1909 (39.3\%) \\
\hline \multicolumn{4}{|l|}{ On-label indications ${ }^{\mathrm{b}} ; \mathrm{n}(\%)$} \\
\hline Epilepsy & $243(7.6 \%)$ & 306 (I8.8\%) & $550(11.3 \%)$ \\
\hline Neuropathic pain & $1326(4 \mid .2 \%)$ & $778(47.8 \%)$ & $2106(43.4 \%)$ \\
\hline Anxiety disorders & $511(15.9 \%)$ & $124(7.6 \%)$ & $635(13.1 \%)$ \\
\hline Any on-label diagnosis $;$; (\%) & 1777 (55.2\%) & $1004(61.6 \%)$ & $2783(57.4 \%)$ \\
\hline \multicolumn{4}{|l|}{ Co-medication ${ }^{\mathrm{d}} ; \mathrm{n}(\%)$} \\
\hline Opioids & 1565 (48.6\%) & $670(41.1 \%)$ & $2238(46.1 \%)$ \\
\hline Anxiolytics & $548(17.0 \%)$ & $162(9.9 \%)$ & $710(14.6 \%)$ \\
\hline Hypnotics & 445 (13.8\%) & $183(11.2 \%)$ & $628(12.9 \%)$ \\
\hline Antidepressants & 1202 (37.3\%) & $485(29.8 \%)$ & 1687 (34.8\%) \\
\hline Antipsychotics & $108 \mid(33.6 \%)$ & $414(25.4 \%)$ & $1496(30.8 \%)$ \\
\hline Different ATC codes; Median (IQR) & $9(7-12)$ & $8(6-11)$ & $9(6-11)$ \\
\hline
\end{tabular}

Notes: ${ }^{a}$ Four persons received pregabalin and gabapentin on the day of the index prescription. ${ }^{b}$ Assessed in the quarter of the index prescription and the preceding quarter, allowing multiple diagnoses per patient. ${ }^{\mathrm{C}}$ Pregabalin: epilepsy, neuropathic pain, anxiety disorders, gabapentin: epilepsy, neuropathic pain. ${ }^{\mathrm{d}}$ Assessed in the 30 days before until 30 days following the index prescription.

Abbreviations: ATC, Anatomical Therapeutic Chemical; IQR, interquartile range.

\section{Baseline Characteristics Of New Users}

In this new user cohort $(\mathrm{n}=4852)$, median age at the time of the index prescription was 84 years and $78.5 \%$ of the patients were female (Table 1). There were no noticeable differences between new users of pregabalin and gabapentin in terms of baseline characteristics. Pregabalin initiators were somewhat more caredependent, but gabapentin users were more likely to be diagnosed with renal disease.

About $46 \%$ of the patients received opioids during the time period 30 days before until 30 days following the index prescription, respectively. Pregabalin initiators were more likely to receive opioids than gabapentin initiators (48.6\% vs $41.1 \%)$. Pregabalin users also more often received anxiolytic, hypnotic, antidepressant, and antipsychotic treatment.

\section{Prescribing Patterns Of New Users}

Table 2 indicates that about two-thirds of patients received their first gabapentinoid prescription from a general practitioner (GP) followed by $20.3 \%$ initiating treatment prescribed by a neurologist, psychotherapist, or psychiatrist. Less than $2 \%$ of the initial prescriptions were made by an anesthesiologist or pain specialist. No differences were found between new users of pregabalin and gabapentin.

About half of pregabalin initiators started treatment with the $25 \mathrm{mg}$ strength (45.4\%) followed by $29.0 \%$ receiving $75 \mathrm{mg}$. Slightly more than half of the gabapentin users $(51.3 \%)$ started treatment with $100 \mathrm{mg}$ followed by $41.0 \%$ receiving $300 \mathrm{mg}$ (Figure 2).

Overall, $27.5 \%$ of the new users received only one gabapentinoid prescription with no differences between both substances (Table 2). Incident gabapentin users were 
Table 2 Utilization Of Gabapentinoids During Nursing Home Stay By Type Of Index Medication(s)

\begin{tabular}{|c|c|c|c|}
\hline & $\begin{array}{l}\text { Pregabalin Users } \\
(\mathrm{N}=3219)\end{array}$ & $\begin{array}{l}\text { Gabapentin Users } \\
(N=1629)\end{array}$ & Total $(\mathrm{N}=4852)^{\mathrm{a}}$ \\
\hline \multicolumn{4}{|l|}{ Physician specialty (first prescription); n (\%) } \\
\hline General practitioner (GP) & $2052(63.8 \%)$ & $1092(67.0 \%)$ & $3148(64.9 \%)$ \\
\hline Neurologist/psychotherapist/ & $610(19.0 \%)$ & $373(22.9 \%)$ & $983(20.3 \%)$ \\
\hline \multicolumn{4}{|l|}{ psychiatrist } \\
\hline Anaesthesiologist/ & $56(1.7 \%)$ & $26(1.6 \%)$ & $82(1.7 \%)$ \\
\hline \multicolumn{4}{|l|}{ pain specialist } \\
\hline Other specialties & $78(2.4 \%)$ & $56(3.4 \%)$ & $134(2.8 \%)$ \\
\hline Missing/unknown & $423(13.1 \%)$ & $82(5.0 \%)$ & $505(10.4 \%)$ \\
\hline \multicolumn{4}{|l|}{ Change of treatment; $n(\%)$} \\
\hline One prescription only & $897(27.9 \%)$ & $435(26.7 \%)$ & 1332 (27.5\%) \\
\hline Change of substance & $97(3.0 \%)$ & $112(6.9 \%)$ & $213(4.4 \%)$ \\
\hline Multiple prescriptions, same strength & $1568(48.7 \%)$ & $814(50.0 \%)$ & $2382(49.1 \%)$ \\
\hline Multiple prescriptions, different strengths & $657(20.4 \%)$ & $268(16.5 \%)$ & $925(19.1 \%)$ \\
\hline Number of packages; Median (IQR) & $3(1-8)$ & $4(I-9)$ & $3(1-9)$ \\
\hline Number of DDDs; Median (IQR) & $39(17-108)$ & $42(17-133)$ & $42(17-120)$ \\
\hline \multicolumn{4}{|l|}{ Percentage of days covered ${ }^{b}$} \\
\hline Assuming a daily dose of one DDD; Median (IQR) & $27(11-53)$ & $21(8-49)$ & $25(10-52)$ \\
\hline Assuming 3 units per day; Median (IQR) ${ }^{c}$ & $66(28-100)$ & $74(30-100)$ & $68(29-100)$ \\
\hline
\end{tabular}

Notes: a Four persons received pregabalin and gabapentin on the day of the index prescription. ${ }^{b}$ Since in-hospital medication is supplied by the hospital and not covered by the data, the number of days a patient was hospitalized was excluded from the denominator. ${ }^{\mathrm{C}}$ One unit corresponds to one tablet or one capsule irrespective of its strength or - in the rare case of the use of pregabalin liquid $-2.5 \mathrm{~mL}(=50 \mathrm{mg})$.

Abbreviations: DDD, defined daily dose; GP, general practitioner; IQR, interquartile range.

more likely to switch to the other agent than those receiving pregabalin as index prescription ( $6.9 \%$ vs $3.0 \%)$. About half of gabapentinoid initiators stayed on their initial strength (pregabalin: $48.7 \%$ and gabapentin: $50.0 \%$ ).

Across the study period, patients received a median number of 3 packages (IQR: 1-9) with a median number of 42 DDDs (IQR: 17-120; Table 2). The median proportion of days during nursing home stay that were covered with gabapentinoids was $27 \%$ (IQR: $11-53 \%$ ) for pregabalin and 21\% (IQR: $8-49 \%$ ) for gabapentin initiators (Table 2). Assuming that the drug was administered three times a day led to a far higher proportion of days covered (66\% for pregabalin and $74 \%$ for gabapentin).

\section{Indications And Diagnoses For On- And Off-Label Use}

Epilepsy was found in $7.6 \%$ of the pregabalin users and in $18.8 \%$ of the patients initiating gabapentin. Similarly, neuropathic pain as potential indication was observed less often in pregabalin-treated patients $(41.2 \%)$ than in those receiving gabapentin (47.8\%). In contrast, anxiety disorders were more often diagnosed in users of pregabalin compared to patients using gabapentin (15.9\% vs 7.6\%). Overall, on-label diagnoses were found in $55.2 \%$ of the pregabalin and in $61.6 \%$ of the gabapentin users (Table 1).

When looking at the 2069 residents (42.6\%) without a licensed indication, painful conditions other than neuropathic pain were diagnosed in $84.7 \%$ of the patients (Table 3). Back pain and arthritis were the most common off-label pain diagnoses, and no noticeable differences were found for those treated with pregabalin and gabapentin. In these patients with only off-label indications, depression was found in $42.4 \%$ of the pregabalin and $39.2 \%$ of the gabapentin initiators.

\section{Discussion}

Increased prescription rates for gabapentinoids have been reported both in Europe and the USA. ${ }^{19,20}$ This general trend is possibly mirrored in the frequent prescribing of gabapentin and pregabalin for nursing home residents in Germany noticed in the present study. In our five-year observational period, the overall prescription prevalence of gabapentinoids was $7.5 \%$ which was remarkably similar to what has recently been reported for a US cohort $(7.8 \%) .{ }^{21}$ Further, prescriptions were nearly equally frequent for on- and off-label indications. Most importantly, 

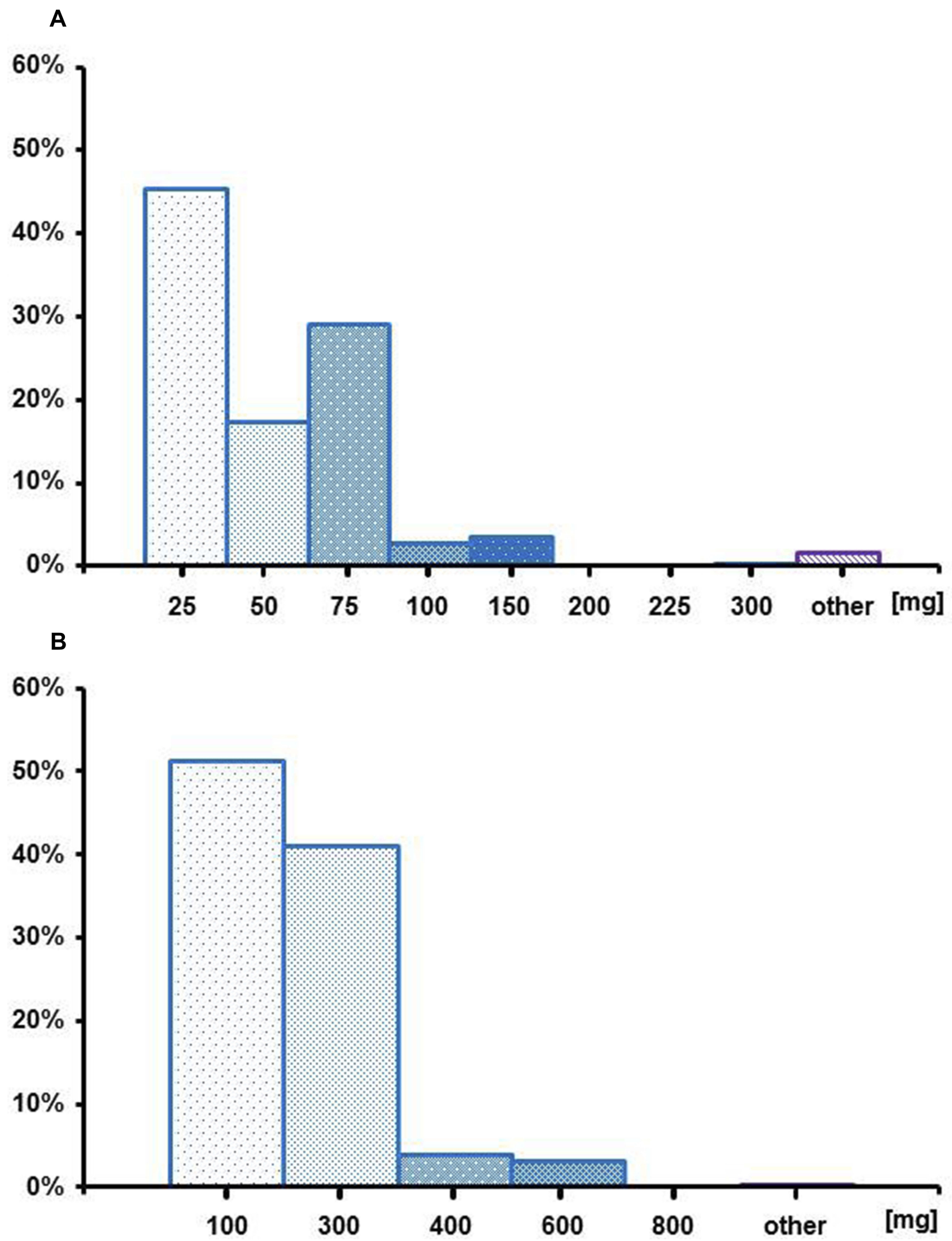

Figure 2 Strength of the index prescription in gabapentinoid initiators.

Notes: (A) Data shown for pregabalin; (B) Data shown for gabapentin; other: any other dose. 
Table 3 Potential Indications For Gabapentinoid Use In Patients With Only Off-Label Indications By Index Prescription

\begin{tabular}{|l|l|l|l|}
\hline & Pregabalin Users (N = I442) & Gabapentin Users (N = 625) & Total (N = 2069) \\
\hline Pain; $n$ (\%) & & & \\
Back pain & $783(54.3 \%)$ & $360(57.6 \%)$ & $1145(55.3 \%)$ \\
Arthritis (osteoarthritis; rheumatoid) & $563(39.0 \%)$ & $269(43.0 \%)$ & $833(40.3 \%)$ \\
Traumatic fractures & $204(14.2 \%)$ & $82(13.1 \%)$ & $286(13.8 \%)$ \\
Headache & $54(3.7 \%)$ & $23(3.7 \%)$ & $79(3.8 \%)$ \\
Cancer & $323(22.4 \%)$ & $115(18.4 \%)$ & $439(21.2 \%)$ \\
Pain associated with multimorbidy/care-dependence) & $392(27.2 \%)$ & $133(21.3 \%)$ & $525(25.4 \%)$ \\
Other pain & $493(34.2 \%)$ & $206(33.0 \%)$ & $702(33.9 \%)$ \\
\hline Any pain diagnosis; $n$ (\%) & $531(85.0 \%)$ & $1752(84.7 \%)$ \\
\hline Other off-label uses; $n$ (\%) & $1219(84.5 \%)$ & & $858(41.5 \%)$ \\
Depression & & $245(39.2 \%)$ & $171(8.3 \%)$ \\
Substance abuse (alcohol; benzodiazepine) & $116(8.0 \%)$ & $55(8.8 \%)$ & $62(3.0 \%)$ \\
Restless legs syndrome & $39(2.7 \%)$ & $23(3.7 \%)$ & \\
\hline
\end{tabular}

Notes: ${ }^{\mathrm{a} T w o}$ persons received pregabalin and gabapentin on the day of the index prescription. ${ }^{\mathrm{b}}$ Assessed in the quarter of the index prescription and the preceding quarter, allowing multiple diagnoses per patient. ${ }^{\circ}$ Other than neuropathic.

however, in either case, they were almost exclusively employed for the management of pain. Of all patients with at least one on-label prescription, three quarters were prescribed gabapentinoids for neuropathic pain, while $85 \%$ of the off-label uses were for other painful conditions. Interestingly, both drugs were mostly prescribed by general practitioners $(65 \%)$ and surprisingly little by pain specialists $(<2 \%)$.

\section{Prescribing Of Gabapentinoids}

Although the reasons for the increased use of gabapentinoids remain unclear, a lack of effect of opioids in certain pain conditions as well as the current opioid epidemic in the USA might motivate doctors to increasingly seek alternative treatments. ${ }^{19}$ The high proportion of off-label use of gabapentinoids for pain management observed in this study supports the notion of doctors searching for alternatives to opioids. The idea is further maintained by our finding that in about a quarter of patients gabapentinoids were prescribed only once, which might indicate either a failed trial to manage pain with these medications or a termination of treatment due to unwanted effects. Finally, the considerable proportion of co-prescriptions with opioids seen here might be the result of doctors trying to limit opioid consumption through the employment of multimodal pharmacological strategies. Evidence to support possible opioid-sparing properties of gabapentinoids has been provided repeatedly by meta-analyses. ${ }^{5,22,23}$ However, Kharash and Eisenach in a recent editorial contend the clinical value of these effects and emphasize the need for more research in this regard. ${ }^{12}$

A further but so far under-recognized reason for the high prescription volumes of gabapentinoids in nursing homes in Germany might be their employment as pharmacological remedy to the staffing problems in nursing homes and hospitals. ${ }^{24}$ Overworked staff might use the drugs' sedative properties to calm patients and to consequently reduce their own workload. ${ }^{25}$ This is reminiscent to what Lucas et al suggested as reasons for the frequent off-label prescribing of antipsychotics in nursing homes. ${ }^{26}$

The almost exclusive prescribing of gabapentinoids by GPs might highlight yet another issue - the lack of accessibility of elderly patients to pain management specialists. Because elderly patients are often frail and hampered by comorbidities, they are frequently restricted in their physical mobility. In addition, even if mobile, there might be a shortage of trained physicians and practice guidelines to sufficiently manage pain in this patient cohort. ${ }^{27}$

\section{Marketing Of Gabapentinoids}

Goodman and Brett suggest industry's aggressive marketing strategies might contribute to the increased prescribing rates of gabapentinoids. ${ }^{19}$ Data to support this notion are usually difficult to obtain but the high proportion of offlabel use and the less frequent prescriptions for gabapentin which is available as a generic since 2004 might indicate it indeed could have been a contributing factor. The notion is further supported by reports showing pharmaceutical companies in Germany and the USA are spending considerably 
on advertisements. ${ }^{28,29}$ Here industry predominantly focuses on prescribing physicians through a variety of promotional strategies. ${ }^{30}$ Despite some initiatives to reduce the influence of companies, sponsoring of educational events and experts, for instance, is still common place in Germany and hence increasingly criticized. ${ }^{31}$ That non-medical reasons might contribute to the frequent off-label prescribing is also indirectly supported by experts. They recently highlighted that the present evidence is not sufficient to warrant the use of gabapentinoids for off-label indications. ${ }^{12,19}$ Their contention is based on meta-analyses showing a limited effectiveness of gabapentinoids to treat for instance low back and lumbar radicular pain, ${ }^{32}$ chronic non-specific back $^{33}$ as well as cancer pain. $^{34}$

\section{Adverse Events}

Although gabapentin and pregabalin have similar pharmacodynamic properties, their pharmacokinetics are considerably different. The intestinal absorption of gabapentin, for instance, is saturable reducing its bioavailability dosedependently from $80 \%$ at $100 \mathrm{mg}$ to $27 \%$ at $1600 \mathrm{mg}$. Conversely, pregabalin shows a linear intestinal uptake rendering its bioavailability constant at $\geq 90 \%{ }^{7}$ Gabapentinoids are widely regarded as safe and well tolerated. ${ }^{7}$ This notion is based on their lack of protein binding and no known interference with major cytochrome $\mathrm{P} 450$ isoenzymes in the liver making drug interactions seem unlikely. ${ }^{2}$ Nevertheless, dose reductions are recommended in renal impairment as both drugs are eliminated mostly unchanged via renal excretion. ${ }^{2,7}$

The reputation of gabapentin and pregabalin as usually benign medications might have contributed also to the high prescription prevalence and incidence observed here. However, there is increasing evidence to suggest this reputation might need revision especially in the elderly population. A recent meta-analysis, for instance, found the initiation of pregabalin was associated with an increased risk of cognitive impairment and problems with coordination. ${ }^{35}$ As similar adverse events have also been described for gabapentin, these medications might hence put elderly patients at a considerably higher risk of falls and aggravation of cognitive problems. ${ }^{11,36}$ Recent evidence further indicates gabapentin and pregabalin might increase the possibility for developing atrial fibrillation in the elderly population. ${ }^{37}$

Further, in peri-operative medicine, concerns about an increased risk of respiratory depression as a consequence of possible interactions of gabapentinoids with opioids have been raised. ${ }^{12}$ Although extrapolations to elderly people in nursing homes are not unproblematic, these concerns might nevertheless highlight a yet under-recognized issue in this cohort of vulnerable patients. It also has led to a warning from the UK Medicines and Healthcare products Regulatory Agency (MHRA) in October 2017 that although rare, elderly patients might be at increased risk of respiratory depression when receiving gabapentin together with opioids. ${ }^{38}$ Additional concerns have been raised about the risk of misuse and addiction associated with gabapentinoids. The authors of an Australian study therefore warn against an offlabel use of pregabalin. $^{39}$ Moreover, the US Drug Enforcement Administration (DEA) has declared pregabalin as a schedule $\mathrm{V}$ drug in 2005 and it is recommended both gabapentin and pregabalin should be avoided in patients with a history of substance use disorder. ${ }^{40,41}$ Similarly, with effect from April 1, 2019, the UK government has labeled pregabalin and gabapentin as Class $C$ substances and placed them in Schedule 3 under the 'Misuse of Drugs Regulations $2001{ }^{\prime}{ }^{42}$ Both compounds have therefore become controlled drugs.

Finally, the observed $27.5 \%$ prevalence of once-only prescriptions of gabapentinoids observed in this study might be a consequence of the occurrence of intolerable adverse events and therefore reflect the need to stop their administration. Yet, the frequent low dose initiation of gabapentinoids seen here might either indicate prescribers had some awareness about potential harmful effects and aimed to minimize the risk or they prescribed them for offlabel indications other than pain. However, future studies need to be designed to determine the precise reasons for the high discontinuation and low dose initiation rates.

\section{Study Limitations}

One limitation attributed to the administrative nature of the data is that no direct linkage is possible between prescriptions and corresponding indications thus misclassification cannot be ruled out. Furthermore, there might also be concerns on the validity of diagnoses coded. Information about the drugs' effectiveness or reasons why medications were discontinued cannot be deduced from this database. However, data on prescribing patterns can be obtained, which is a major strength of claims data. Since neither daily doses nor intended durations of treatment are included in the data, we used two different approaches to estimate the time a patient received gabapentinoids. Considering the older study population and the mainly lower strengths dispensed, the defined daily dose probably leads to an underestimation of the duration of treatment and 
the "three units per day approach" might reflect the duration of treatment more accurately.'

Another limitation was that the data were received from one statutory health insurance only. As it nevertheless included a considerable number of patients and since health insurance companies and general practitioners in Germany by and large offer similar services, additional data from other companies would unlikely have changed results. Moreover, the "DAK-Gesundheit" covers all sixteen German states.

Finally, there were also no data available that could have provided insights into the mental models and decision-making processes of the prescribing physicians. Future studies should investigate this underreported but important aspect of care provision similar to what has been started with opioids. ${ }^{43,44}$

\section{Conclusion}

A considerable proportion of nursing home residents in Germany either initiated gabapentinoids during their stay (4.0\% prescription incidence) or received at least one prescription (7.5\% prescription prevalence). Both drugs were used for on- as well as off-label indications. About half $(43 \%)$ of all on-label prescriptions were for pain conditions (neuropathic pain), while pain other than neuropathic pain was the reason for off-label prescriptions in $84 \%$ of the cases. This high proportion of other than neuropathic pain conditions as reason for the employment of gabapentinoids in German nursing homes is despite increasing concerns about their effectiveness in some pain conditions and their safety profile in elderly patients. Particularly their psychotropic properties might expose the vulnerable older person to risk of falls. Therefore, more research is needed before a further widespread use of gabapentinoids in pain management can be advocated in general and especially in elderly patients.

\section{Acknowledgment}

The authors thank the DAK-Gesundheit for providing the data for this study.

\section{Author Contributions}

$\mathrm{CB}$ designed the study and wrote the manuscript. KJ designed the study, analyzed the data and wrote the manuscript. FH designed the study, analyzed the data and wrote the manuscript. All authors contributed to data analysis, drafting and revising the article, gave final approval of the version to be published, and agree to be accountable for all aspects of the work.

\section{Disclosure}

The authors report no conflicts of interest in this work.

\section{References}

1. Sills GJ. The mechanisms of action of gabapentin and pregabalin. Curr Opin Pharmacol. 2006;6(1):108-113. doi:10.1016/j.coph.2005.11.003

2. Calandre EP, Rico-Villademoros F, Slim M. Alpha2delta ligands, gabapentin, pregabalin and mirogabalin: a review of their clinical pharmacology and therapeutic use. Expert Rev Neurother. 2016;16 (11):1263-1277. doi:10.1080/14737175.2016.1202764

3. Fullerton CA, Busch AB, Frank RG. The rise and fall of gabapentin for bipolar disorder: a case study on off-label pharmaceutical diffusion. Med Care. 2010;48(4):372-379. doi:10.1097/MLR.0b013e3181ca404e

4. Supasitthumrong T, Bolea-Alamanac BM, Asmer S, Woo VL, Abdool PS, Davies SJC. Gabapentin and pregabalin to treat aggressivity in dementia: a systematic review and illustrative case report. $\mathrm{Br}$ J Clin Pharmacol. 2019;85(4):690-703. doi:10.1111/bcp.13844

5. Mishriky BM, Waldron NH, Habib AS. Impact of pregabalin on acute and persistent postoperative pain: a systematic review and meta-analysis. Br J Anaesth. 2015;114(1):10-31. doi:10.1093/bja/ aeu293

6. Sofat N, Harrison A, Russell MD, et al. The effect of pregabalin or duloxetine on arthritis pain: a clinical and mechanistic study in people with hand osteoarthritis. J Pain Res. 2017;10:2437-2449. doi:10.2147/JPR.S147640

7. Bockbrader HN, Wesche D, Miller R, Chapel S, Janiczek N, Burger P. A comparison of the pharmacokinetics and pharmacodynamics of pregabalin and gabapentin. Clin Pharmacokinet. 2010;49 (10):661-669. doi:10.2165/11536200-000000000-00000

8. Martin R, Meador K, Turrentine L, et al. Comparative cognitive effects of carbamazepine and gabapentin in healthy senior adults. Epilepsia. 2001;42(6):764-771. doi:10.1046/j.1528-1157.2001.33300.x

9. Haslam C, Nurmikko T. Pharmacological treatment of neuropathic pain in older persons. Clin Interv Aging. 2008;3(1):111-120. doi:10.2147/CIA.S1681

10. Schmader KE, Baron R, Haanpaa ML, et al. Treatment considerations for elderly and frail patients with neuropathic pain. Mayo Clin Proc. 2010;85(3 Suppl):S26-32. doi:10.4065/mcp.2009.0646

11. Randolph AC, Lin YL, Volpi E, Kuo YF. Tricyclic antidepressant and/or gamma-aminobutyric acid-analog use is associated with fall risk in diabetic peripheral neuropathy. J Am Geriatr Soc. 2019;67 (6):1174-1181. doi:10.1111/jgs.15779

12. Kharasch ED, Eisenach JC. Wherefore gabapentinoids?: was there rush too soon to judgment? Anesthesiology. 2016;124(1):10-12. doi:10.1097/ALN.0000000000000914

13. Curkovic M, Dodig-Curkovic K, Eric AP, Kralik K, Pivac N. Psychotropic medications in older adults: a review. Psychiatr Danub. 2016;28(1):13-24.

14. Kaye AD, Baluch A, Scott JT. Pain management in the elderly population: a review. Ochsner J. 2010;10(3):179-187.

15. Lyrica ${ }^{\circledR}$ (Pregabalin) Hartkapseln. Fachinformation. Berlin, Germany: Pfizer GmbH; 2018.

16. Neurontin ${ }^{\circledR}$ (Gabapentin) 100/300/400 mg Hartkapseln. Fachinform ation. Berlin, Germany: Pfizer GmbH; 2018.

17. Freytag A, Schiffhorst G, Thoma R, et al. Identification and grouping of pain patients according to claims data. Schmerz. 2010;24 (1):12-22. doi:10.1007/s00482-009-0861-y

18. Newcombe R, Altman D. Proportion and their differences. In: Altman D, Machin D, Bryant T, Gardner M, editors. Statistics with Confidence: Confidence Intervals and Statistical Guidelines. 2nd ed. London: BMJ Books; 2000:45-56.

19. Goodman CW, Brett AS. Gabapentin and pregabalin for pain - is increased prescribing a cause for concern? N Engl J Med. 2017;377 (5):411-414. doi:10.1056/NEJMp1704633 
20. Baftiu A, Johannessen Landmark C, Rusten IR, Feet SA, Johannessen SI, Larsson PG. Changes in utilisation of antiepileptic drugs in epilepsy and non-epilepsy disorders-a pharmacoepidemiological study and clinical implications. Eur J Clin Pharmacol. 2016;72(10):1245-1254. doi:10.1007/s00228-016-2092-3

21. Bathena SPR, Leppik IE, Kanner AM, Birnbaum AK. Antiseizure, antidepressant, and antipsychotic medication prescribing in elderly nursing home residents. Epilepsy Behav. 2017;69:116-120. doi:10.1016/j.yebeh.2017.01.027

22. Fabritius ML, Strom C, Koyuncu S, et al. Benefit and harm of pregabalin in acute pain treatment: a systematic review with meta-analyses and trial sequential analyses. Br J Anaesth. 2017;119 (4):775-791. doi:10.1093/bja/aex227

23. Dahl JB, Nielsen RV, Wetterslev J, et al. Post-operative analgesic effects of paracetamol, NSAIDs, glucocorticoids, gabapentinoids and their combinations: a topical review. Acta Anaesthesiol Scand. 2014;58(10):1165-1181. doi:10.1111/aas.12382

24. Altenheime und Kliniken melden über 36.000 unbesetzte Stellen. Zeit Online 2018. Available from: https:/www.zeit.de/wirtschaft/2018-04/ pflege-kranke-altenheime-kliniken-notstand-bundesregierung. Accessed June 26, 2019.

25. Watzlawik H Tabuthema Pflegemängel“; 2003. Available from: https://www.kritischebioethik.de/cdu-pflegefachgespraech-24-06-03. pdf. Accessed June 26, 2019.

26. Lucas JA, Chakravarty S, Bowblis JR, et al. Antipsychotic medication use in nursing homes: a proposed measure of quality. Int $J$ Geriatr Psychiatry. 2014;29(10):1049-1061. doi:10.1002/gps.4098

27. Rastogi R, Meek BD. Management of chronic pain in elderly, frail patients: finding a suitable, personalized method of control. Clin Interv Aging. 2013;8:37-46. doi:10.2147/CIA.S30165

28. Habich I Ausgaben für Arneimittelwerbung steigen. DAZ. online 2016; Available from: https:/www.deutsche-apotheker-zeitung.de/news/artikel/ 2016/05/12/ausgaben-fur-arneimittelwerbung-steigen. Accessed June 26, 2019.

29. Entis L. DTC pharma ad spending slipped $4.6 \%$ in 2017. $M M \& M$. 2018. Available from: https://www.mmm-online.com/commercial/dtcpharma-ad-spending-slipped-46-in-2017-kantar/article/750421/. Access ed June 26, 2019.

30. Bantel C, Laycock HC. Between evidence and commerce - the case of sufentanil sublingual tablet systems. Anaesthesia. 2018;73 (2):143-147. doi:10.1111/anae.14037

31. Keuchel J Das umstrittene Geschäft mit Ärztefortbildungen. Handelsblatt; 2018. Available from: https://www.handelsblatt.com/unternehmen/mittel stand/medizin-das-umstrittene-geschaeft-mit-aerztefortbildung en/23009224.html?ticket=ST-3097501-FT0c3mmcohHzjO0jN7Q7-ap5. Accessed September 26, 2019.

32. Enke O, New HA, New $\mathrm{CH}$, et al. Anticonvulsants in the treatment of low back pain and lumbar radicular pain: a systematic review and meta-analysis. CMAJ. 2018;190(26):E786-E793. doi:10.1503/cmaj.171333
33. Shanthanna H, Gilron I, Rajarathinam M, et al. Benefits and safety of gabapentinoids in chronic low back pain: a systematic review and meta-analysis of randomized controlled trials. PLoS Med. 2017;14 (8):e1002369. doi:10.1111/j.1528-1167.2010.02966.x

34. Kane CM, Mulvey MR, Wright S, Craigs C, Wright JM, Bennett MI. Opioids combined with antidepressants or antiepileptic drugs for cancer pain: systematic review and meta-analysis. Palliat Med. 2018;32(1):276-286. doi:10.1177/0269216317711826

35. Zaccara G, Gangemi P, Perucca P, Specchio L. The adverse event profile of pregabalin: a systematic review and meta-analysis of randomized controlled trials. Epilepsia. 2011;52(4):826-836. doi:10.1111/j.1528-1167.2010.02966.x

36. Wiffen PJ, Derry S, Bell RF, et al. Gabapentin for chronic neuropathic pain in adults. Cochrane Database Syst Rev. 2017;6:CD007938. doi:10.1002/14651858.CD007938.pub4.

37. Ortiz de Landaluce L, Carbonell P, Asensio C, Escoda N, Lopez P, Laporte JR. Gabapentin and pregabalin and risk of atrial fibrillation in the elderly: a population-based cohort study in an electronic prescription database. Drug Saf. 2018. doi:10.1007/s40264-018-0695-6

38. Government United Kingdom. Gabapentin (Neurontin): risk of severe respiratory depression. Drug Safety Update 2017. Available from: www.gov.uk/drug-safety-update/gabapentin-neurontin-risk-of-severerespiratory-depression. Accessed June 26, 2019.

39. Cairns R, AL S, Ryan N, SA P, Buckley NA. Rising pregabalin use and misuse in Australia: trends in utilization and intentional poisonings. Addiction. 2019;114(6):1026-1034. doi:10.1111/add.14412

40. Bonnet U, Scherbaum N. How addictive are gabapentin and pregabalin? A systematic review. Eur Neuropsychopharmacol. 2017;27 (12):1185-1215. doi:10.1016/j.euroneuro.2017.08.430

41. US Department of Justice. Schedules of controlled substances: placement of pregabalin into schedule V; 2005. Available from: https://www. deadiversion.usdoj.gov/fed_regs/rules/2005/fr0728.htm. Accessed June 26, 2019.

42. Government United Kingdom. Pregabalin (Lyrica), gabapentin (Neurontin) and risk of abuse and dependence: new scheduling requirements from 1 April 2019. Available from: https://www.gov. uk/drug-safety-update/pregabalin-lyrica-gabapentin-neurontin-andrisk-of-abuse-and-dependence-new-scheduling-requirements-from -1-april. Accessed September 12, 2019.

43. Gardiner C, Gott M, Ingleton C, Hughes P, Winslow M, Bennett MI. Attitudes of health care professionals to opioid prescribing in end-oflife care: a qualitative focus group study. J Pain Symptom Manage. 2012;44(2):206-214. doi:10.1016/j.jpainsymman.2011.09.008

44. Ward S, Guest C, Goodall I, Bantel C. Practice and bias in intraoperative pain management: results of a cross-sectional patient study and a survey of anesthesiologists. J Pain Res. 2018;11:561-570. doi:10.2147/JPR. S153857
Journal of Pain Research

\section{Publish your work in this journal}

The Journal of Pain Research is an international, peer reviewed, open access, online journal that welcomes laboratory and clinical findings in the fields of pain research and the prevention and management of pain. Original research, reviews, symposium reports, hypothesis formation and commentaries are all considered for publication. The manuscript management system is completely online and includes a very quick and fair peer-review system, which is all easy to use. Visit http:// www.dovepress.com/testimonials.php to read real quotes from published authors. 